\title{
Back to the Future: Engineering Sketching as Visualization, Idea Generation and Communication Tool
}

\author{
M.J. Eggermont, D.M. Douglas, D.J. Caswell, C.R. Johnston \\ Faculty of Engineering, University of Calgary \\ meggermo@ucalgary.ca
}

\begin{abstract}
Training in engineering drawing has traditionally been focused on learning technical drawing or drafting skills in isolation from analytical and design skills. Engineering 251/253, as taught at the University of Calgary, has developed a visual literacy component that combines drawing methods from Engineering and Fine Art.

Teaching drawing and sketching to first-year engineers, develops both drawing skill and perceptual ability which can be directly applied to current 3-D modeling programs. Engineering drawing or engineering sketching, as it is known in our course, functions as a tool for creativity, design and analysis, rather than strictly for technical representation.
\end{abstract}

\section{Introduction}

"Both the engineer and the artist start with a blank page. Each will transfer to it the vision in the mind's eye"[1].

The Boyer Commission's Report of 1998 called for "a restructuring of undergraduate education at large research institutions. The report emphasized interdisciplinarity, undergraduate participation in research, and the integration of communication skills into course work across the curriculum. At the University of Calgary the recommendations of the Boyer were taken up by the Undergraduate Curriculum Redesign Team. The team's final report, released in May 2003, called for a hands-on, inquiry-based approach to learning, particularly for first year students. The Canadian Engineering Accreditation Board (CEAB) stipulates that every student must have real world, team-oriented, open-ended design experience before graduation (CEAB, 2003)."

Engineering 251/253 (ENGG 251/253), a collaboration of art, engineering and communication, is an interdisciplinary first year engineering design course first implemented in the 2002/2003 academic year in response to these challenges to innovate. The course is built around four pillars: drawing, design, communication, and teamwork.

All 600 students entering the engineering faculty participate in the course for a full year [2].

This paper will describe the drawing and visualization projects that all students complete at the end of their first year of engineering.

Students are involved in the performance of drawing as a means for developing the mind/hand/eye coordination necessary for achieving a high level of visual literacy. Technical drawing components (orthographic, isometric, and oblique) are developed as supporting elements to the evolution of ideas, rather than as an end in themselves. In addition to paraline and perspectivebased projections, the students are also exposed to design concepts such as the golden section (fig. 1), biomimetics, and form follows function.

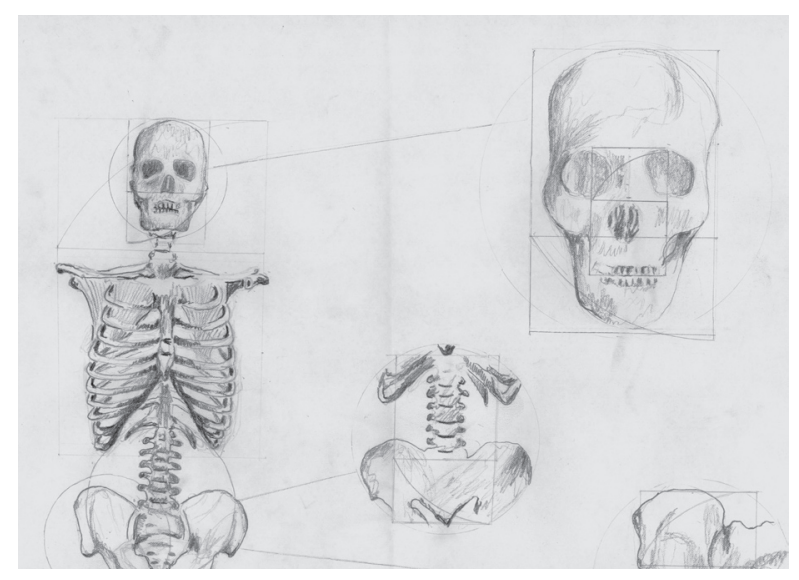

Fig.1: student drawing - golden section in anatomy

\section{Performance drawing}

"I managed to stay as far away from art as I could in High School...that quest ended when I started Engg 251/253."Student quote 
Most students entering their first year in the Engineering faculty do not expect to be drawing with pencil and paper. They have convinced themselves that they do not draw, cannot draw, and will not draw in their future career. Instead, they expect to be given a software program that will do everything for them; idea generation, visualization, and construction.

We begin by introducing the students to basic concepts and historical facts in lecture. They are shown the link between Chinese perspective and oblique drawing; how the introduction of cavelier oblique by Jesuits returned from China seemed ideal for accurate drawings of fortifications in the 17th century. Also, how William Farish put the final touches on the method of isometric projection so it could be used in the ever-expanding assembly shops of the Industrial Revolution.

All major projections are shown in their first drawing lecture and quick sketches of each projection are demonstrated, which the students are required to have in their notes by the end of class. Students are shown the two major groupings of paraline and perspectivebased projections; systems representing what we know and what we see. By the end of the lecture they will be familiar with the relationship between orthographic and isometric, various types of oblique projection (cavalier, cabinet and plan), and the ability to take true measurements from these types of drawings. The students are shown the separate, artistic development in the Italian Renaissance of one, two and three point perspective; a system designed to show what we can see. These concepts and facts are then translated into drawings during the labs. In total, in this full-year course, students are expected to do 11 drawings and projects on their own and one project within a group of four. The drawing assignments are introduced every two weeks, and students have one week to work on a good copy of the sketches that are done in class.

By having the students drawing along with the instructor, they quickly discover that they might, after all, be able to draw. The instructor guides the students through the basic construction of a particular drawing (be it oblique, isometric, orthographic, or perspective) using a document camera. This process is shown to all 600 first-year students spread out over four labs, each of 150 . The 150 students are subsequently divided into teams of four, each having two computer workstations available. The workstations broadcast the document camera feed, allowing them to draw along with the instructor. The students are shown both reductive and additive methods of construction.
The reductive method starts with an outer envelope. Students construct basic drawings by looking for cross sections, basic shapes, and anchor points (to work with when it comes to the more free and fluid areas in the drawing).

The additive construction method is shown when the students have to produce more complex shapes, exploded diagrams (fig. 2), or multiple part drawings.

At the end of each drawing "performance", the instructor circulates through the four lab rooms. The same "performance" happens four times weekly, reaching all 600 students. Students are able to get individual assistance for the remainder of the lab. Individual students with drawing experience were often seen helping fellow students. We found that this formalized knowledge for the helping students and added to the overall environment of inquiry-based learning.

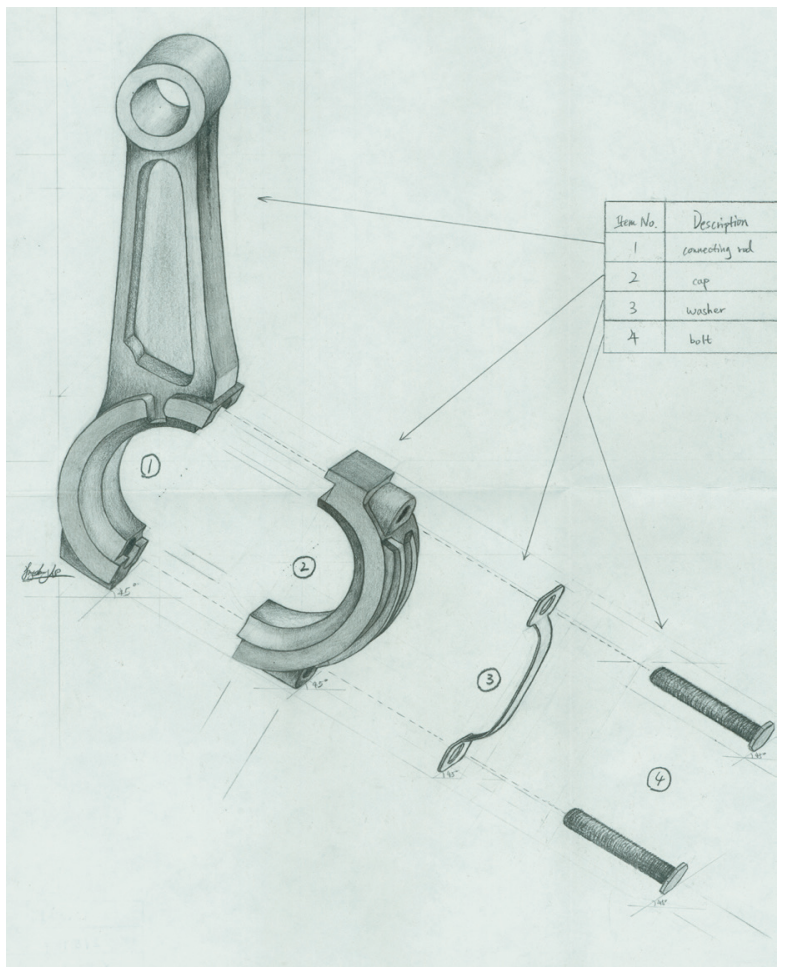

Fig. 2: student drawing - oblique connecting rod

Some questions arose towards the end of the year whether students were actually learning how to draw or learning how to copy. In response, student teams were asked to look at the object (in this case the camshaft of a four stroke motor) and do some sketches. Half an hour into the lab, one student per lab was asked to collaboratively draw the object with his or her fellow students. 
This convinced most sceptics that students had in fact learned to draw on their own (fig. 3).

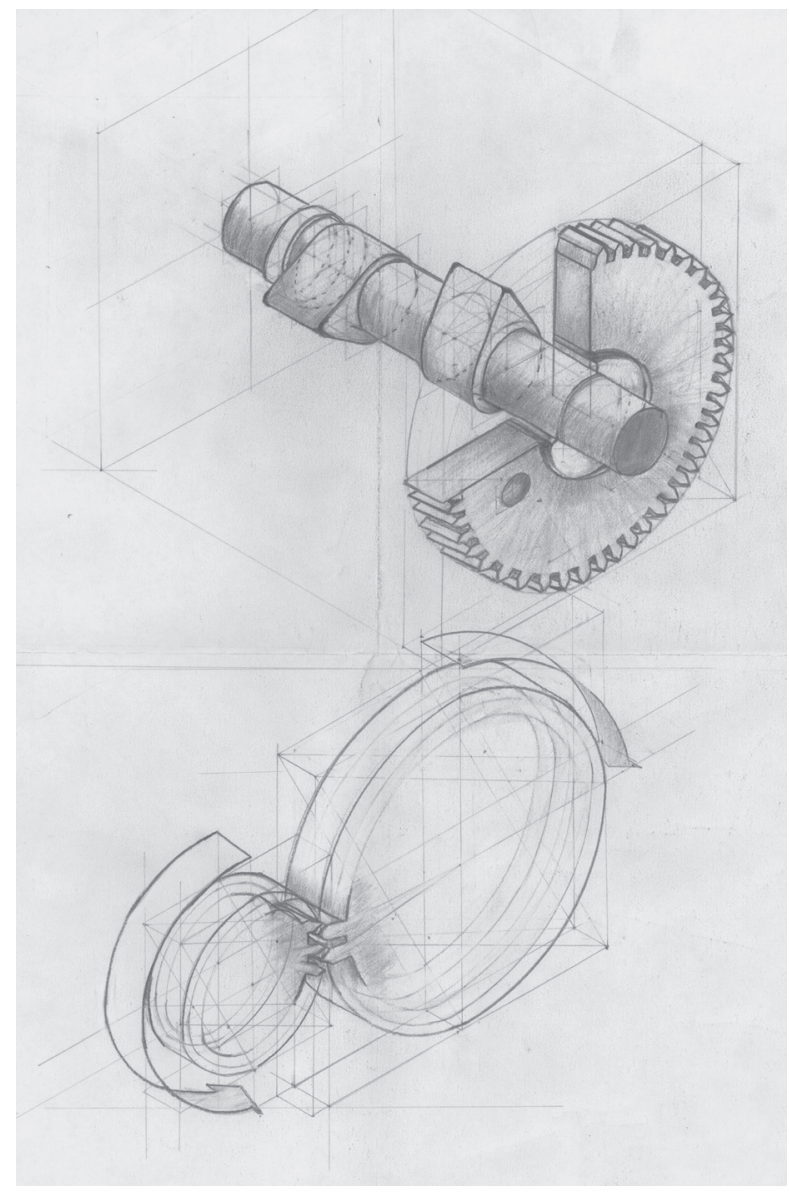

Fig. 3: student drawing - isometric camshaft with gear ratio

A skating robot design project caused the focus on mechanisms in the second half of the course. Students were asked to program and build a robot that could perform a list of functions. Students were introduced to elements of engineering drawings through a sequence of motor parts. Engineering drawing elements included parts lists, dimensioning, sectional views (fig. 4), tolerancing (fig. 5), and gear ratios.

The emphasis of the drawing component is on visualization, which will enable the students to use $3-\mathrm{D}$ modelling software with more efficiency. If a student can "see" the object in advance, the software can be exploited to a much greater extend; the student will bring his or her own creativity, not being limited to the creativity of the programmer. As Ferguson notes: "if designers use commercial computer programs... they turn over all the small and tiny decisions to the programmer, who is more likely to be an 'engineering scientist' than an experienced designer" [3].

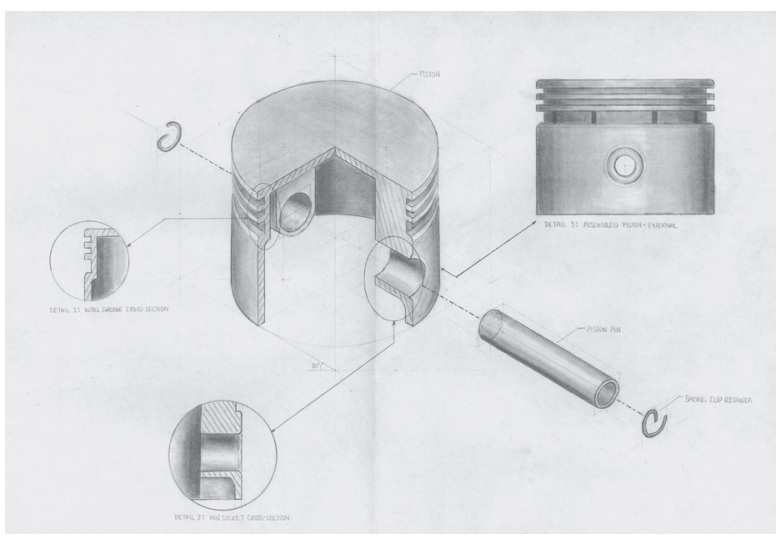

Fig. 4: student drawing - isometric piston

By the end of the year the vast majority of students were able to produce drawings of "good" to "very good" quality. Students showed improved visualization and sketching skills, and an appreciation for the role of drawing in the design process.

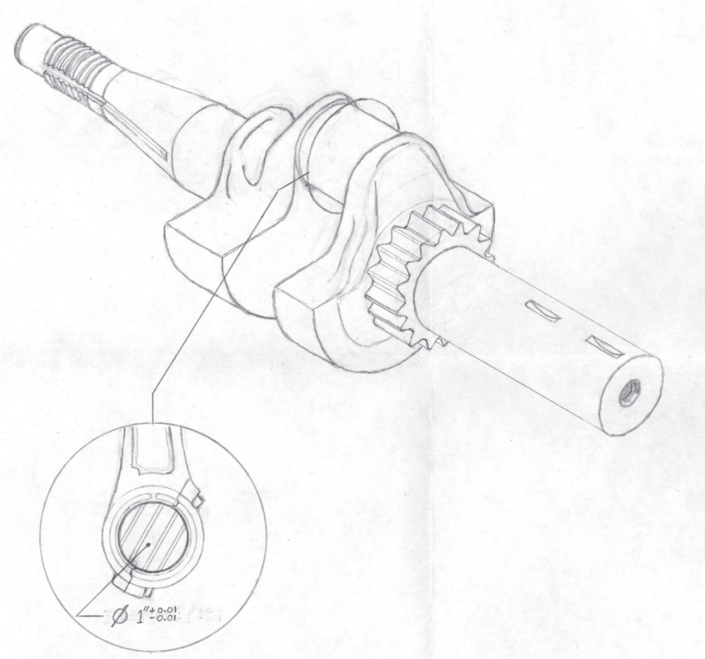

Fig. 5: student drawing - isometric crankshaft

We followed a progression of projections throughout the first semester. Projection drawings were interspersed with assignments that were more abstract in nature and involved some creative problem solving. These assignments are described below. 


\section{Golden Section}

"Fibonacci couldn't sleep Counted rabbits instead of sheep." - K. O’Brien

The golden section assignment was intended to show students how natural proportions can be used in design. The link between the golden section and the Fibonacci sequence was a part of this assignment.

A pair of pliers was drawn in class as an example. Golden section construction showed a relationship between the width of the hand and the length of the handles. Students were subsequently asked to find objects, which were architectural, musical, or natural and show hidden golden sections. The assignment was an eye-opener for the students. Even though the golden section is not the answer to all questions, and is often called into question, it added a sense of wonder to their visualization projects. One student even managed to find the golden ratio in the lyrics of a song by Eminem (fig. 6).

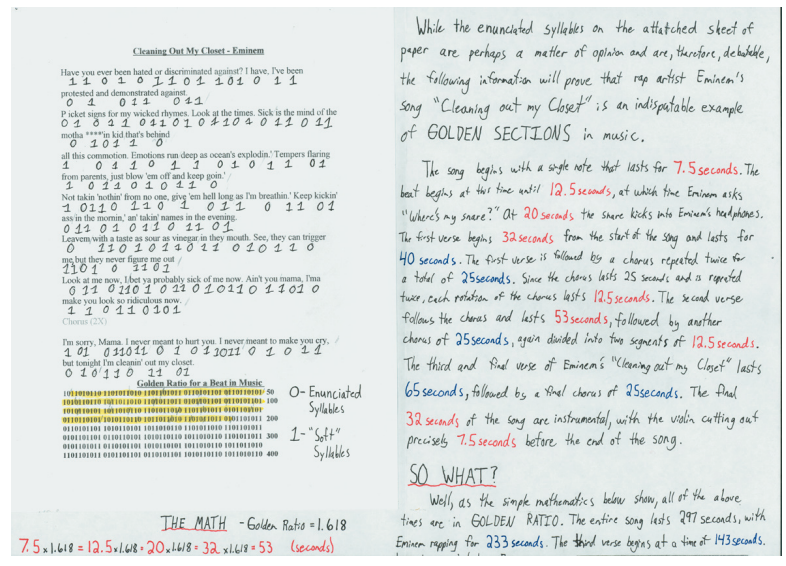

Fig. 6: student work - golden section in Eminem song

\section{Biomimetics}

"Go to the ant, thou sluggard" - proverb

Biomimetics, or the abstraction of good design from nature, was introduced as another approach. An assignment was given to students as an introduction to bionics/biognosis/biomimetics:

Assignment \# 6. Group assignment
Design problem: biomimetic hand tool

Design a biomimetic hand tool (no electric components/ IC engines) that executes one of the following actions:

- Separate

- Sort

- Mix

- Dig

- Fasten/ join

- Aid movement

Interpret these actions as you want and be creative... Design a tool with a new function (a reasonable and potentially workable function) or redesign an existing tool.

Four components should be on your page:

1. One (1) isometric drawing

2. A brief description of your design (include engineering principles)

3. Short bibliography

4. A small image of a source that informed your design

The following questions are things to think about:

- What problem are you trying to solve?

- What kind of tool are you thinking about?

- What does the tool do?

- Which natural systems or organisms solve your problem?

- How does nature deal with the natural laws that concern your "problem"?

- Find as many biological examples as you can that deal with your problem, then choose the one that will help you most.

Please avoid a physical likeness to your source - your isometric drawing should look like a tool, not like a fuzzy creature with ears and a tail that also happens to cut things in half.

This was the only drawing group project of the course. Students were allowed a month for the assignment. The results were good; as was expected, most designs were based on clearly observable natural mechanisms. Designs referenced jaws, beaks, tentacles and claws.

Interestingly, students tried to "sell" their designs to the instructor. Fictional names were given to the products, intending to entice and create excitement: "are you afraid of climbing? Well, fear no more! The CA 2004 Air Gun will shoot you straight to the top" [4]. This for a "new" device, a rappel gun based on a frog's tongue that would (maybe) take a climber up a mountain. 


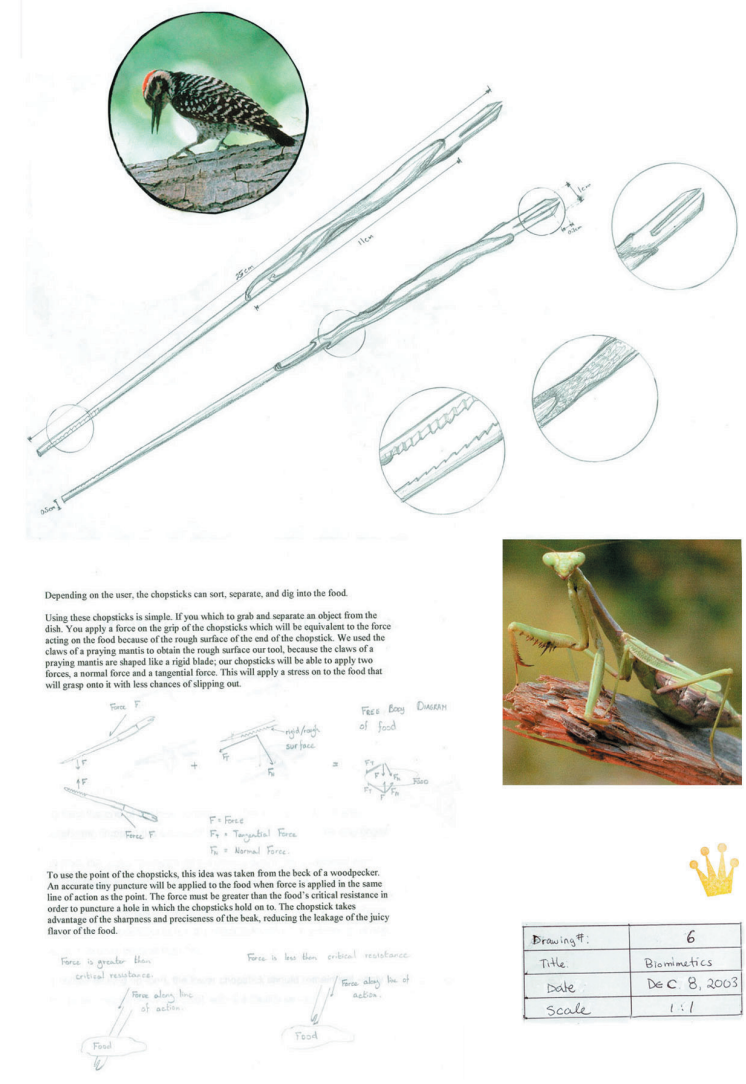

Fig. 7: student project - biomimetics

\section{Form Follows Function}

"It is the pervading law of all things organic and inorganic, of all things physical and metaphysical, of all things human and superhuman, of all true manifestations of the head, of the heart, of the soul, that life is recognizable in its expression, that form ever follows function. This is the law... Are we so decadent, so imbecile, so utterly weak of eyesight, that we cannot perceive this truth so simple, so very simple?"- Louis Sullivan, 1896

"Form follows function" was the dictum that made its way via American architect Louis Sullivan to the European modernists where it was first mentioned in 1934. It has been seen as both the essence of functional design philosophy and as an "empty jingle" (Reyner Banham).
This assignment presented two ends of the spectrum. Students looked for two examples of objects that performed the same function.

It asked them: what is function? One inherent problem with the formulaic "form follows function" is that, as Michl claims, function precedes form; that it exists independently of form, and that it is there before form emerges [5].

Students had varying levels of understanding. Various interpretations of function, comparable to Michl's "actual" and "intended" distinction, resulted in very different choices. Michl sees "actual function" as a term a scientist might have in mind: what does it do, how does it behave, and was there intention or not? He sees "intended function" as the purpose of the object or someone's performance-related intention. This proved to be unexpectedly challenging: it was difficult for the students, and perhaps also for the instructors, to make a clear distinction between "actual" and "intended". Students were forced to think about different levels of functionality (fig 8). At times it became clear that not every student understood what function or functionality actually means, showing assignments like this would have been more useful at the start of the year.

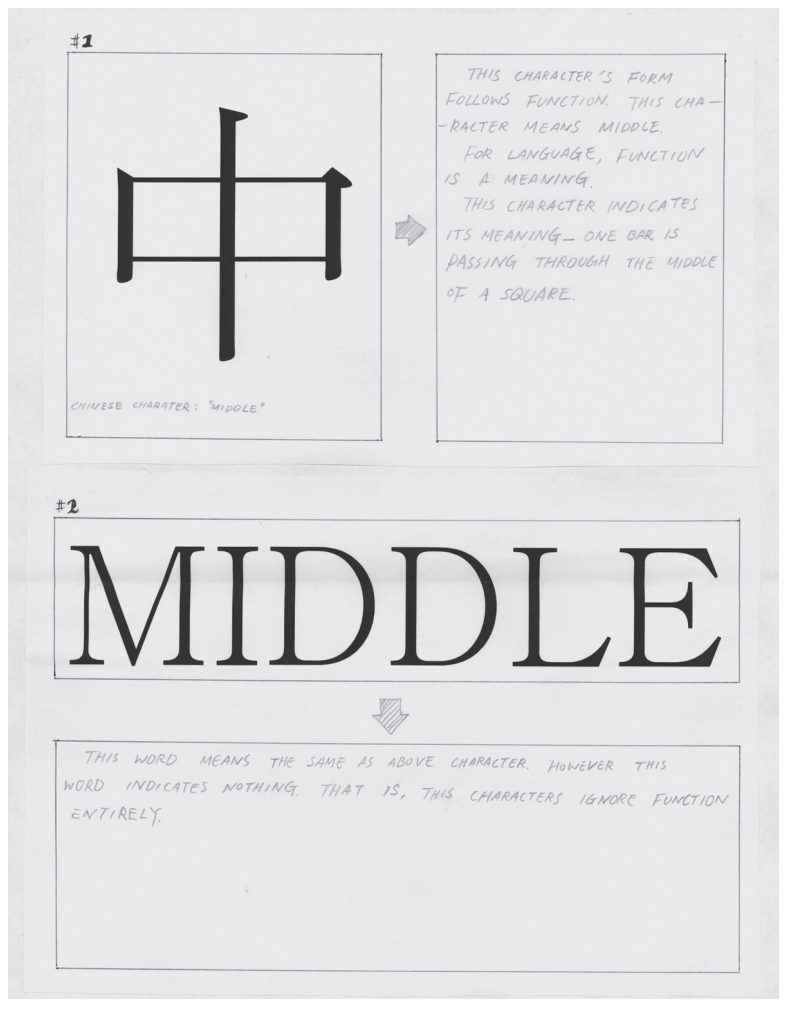

Fig. 8: student work - form follows function/ language 
Another observation was the overwhelming dislike for items deemed to follow the "form follows function" modernist war cry (fig 9). There seemed to be a great love of spoilers, wings, and air intakes - all oversized, under-used, and on the wrong vehicles.

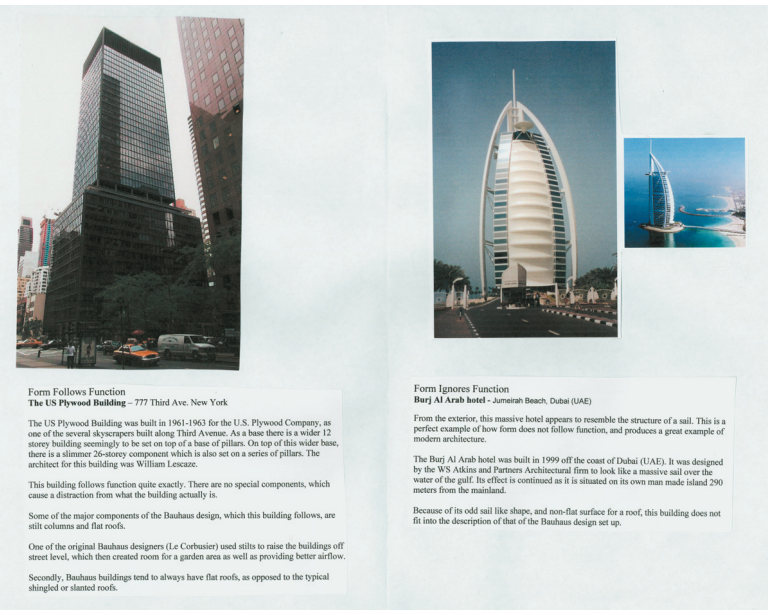

Fig 9: student work - form follows function/ buildings

\section{The Final Assignment}

The final assignment was to draw a mode of transportation and was a chance for the students to show us what they had learned (fig 10, 11).

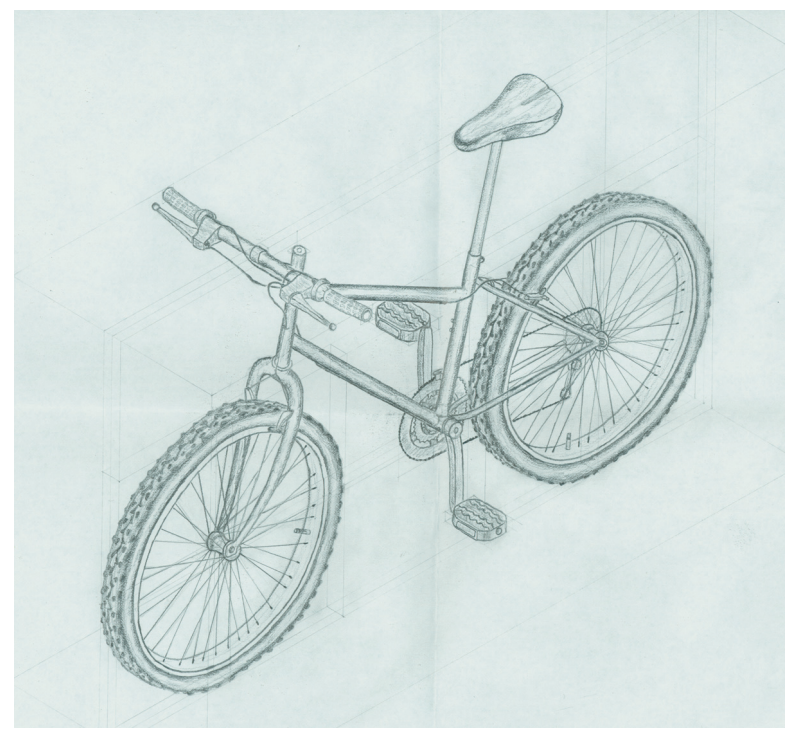

Fig 10: student drawing - transportation
In total over 8,000 drawings were produced from September 2003 till April 2004. A selection of this work (over 250 pieces) was shown in a two-week exhibition, entitled "Projecting back", in the Faculty of Fine Art.

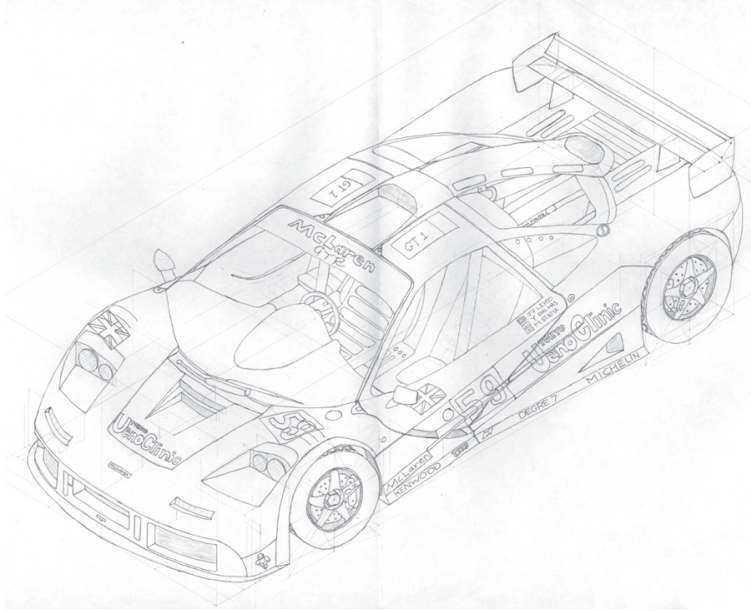

Fig 11: student drawing - transportation

\section{The Follow-up}

"...the ship should not have been asked to demonstrate achievements when she had not had a chance to exhibit her weaknesses"[6].

This past year was the second iteration for Engg 251/253. For the past two years the course has worked with the Olympic Oval in Calgary. Two projects were done with this real world client: the first a crash pad design, and the second the design and programming of a skating robot. The drawing component of the first year focused on anatomical sketches and robotic derivatives of hands and feet. These drawings were intended to have the students consider designs that were anthropomorphic in nature.

As can be seen above, the focus this year was on mechanisms. The students focused on more complex gearing systems when building their robots.

For next year the course has another real world client - the City of Calgary. The drawing component will be adapted accordingly: the students will be asked to look at traffic flow, site design and road entryways at the site of a new children's hospital. The focus will likely be on orthographics, plan obliques and visual displays of quantitative information (as in E. Tufte) in relationship to the new building site. 
A second year course, Graphical Methodologies for Engineering Design, was taught this spring semester. The goal was to see whether the students were able to make greater use of computer software in the same framework. The course integrated art and engineering approaches to design, manual drawing, DS Solidworks, and Adobe Illustrator. Students were introduced to the history of design, elements of form \& composition, graphic design, and design subtlety. Projects were introduced as having art composition content and engineering applications.

The range of students in this course was varied. People from Civil, Mechanical, Manufacturing, and Geomatics Engineering were enrolled, as were a few Fine Arts students. All students were accomplished drawers and were able to translate drawings into Solidworks easily. Adobe Illustrator was mainly used for display and poster purposes. Solidworks files were traced in Illustrator, the advantage being that Illustrator creates size-independant vector files. Graphic design and page layout lectures were given to show the students how visual and written material can be read quickly and efficiently, and how to draw the viewer into a visual display (fig 12).

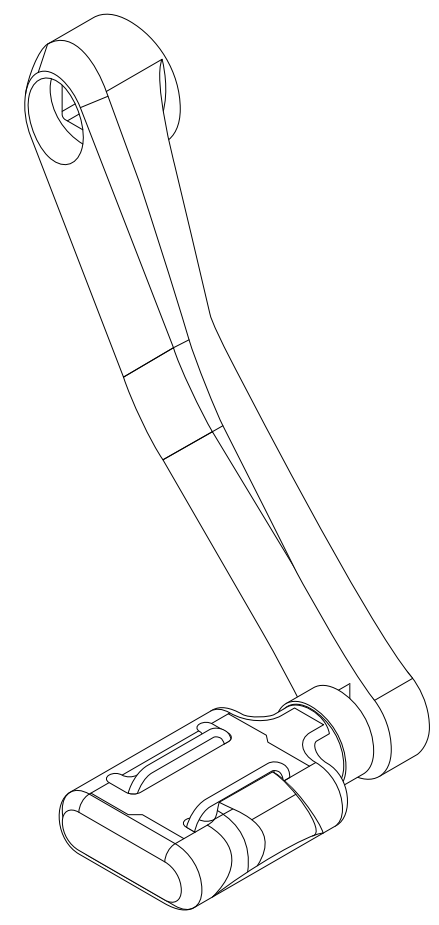

Fig 12: student Adobe Illustrator file

\section{Conclusion}

Training in engineering drawing has traditionally been focused on learning technical drawing or drafting skills in isolation from analytical and design skills. Since the introduction of computer assisted drawing in the 1970's, visualization skills of engineering students have declined.

The drawing component of Engg 251/253 has been called the renaissance component of the course. Even though the drawing component may seem to reintroduce the way things used to be done, we are convinced the approach is new. The students are taught first and foremost to "see" again. Our basis is to involve the students in the performance of drawing as a means for developing the mind/hand/eye coordination necessary for achieving a high level of visual literacy.

\section{References}

[1] Ferguson, E. S., Engineering and the Mind's Eye, The MIT Press, Cambridge, 1993, p. 23.

[2] Caswell, D. et al., "Engg 251/253: Fostering creative problem solving in a multidisciplinary environment", Proceedings of the STLHE conference, June 17 to 19, 2004.

[3] Ferguson, p. 39.

[4] From student work.

[5] Michl, J., "Form Follows WHAT? The modernist notion of function as a carte blanche", 1:50 - Magazine of the Faculty of Architecture \& Town Planning [Technion, Israel Institute of Technology, Haifa, Israel] nr. 10, Winter, 1995: 31-20.

[6] Ferguson, p. 169. 